\title{
Aberrant allele-specific replication, independent of parental origin, in blood cells of cancer patients Zohar A Dotan ${ }^{1}$, Aviva Dotan², Jacob Ramon ${ }^{1}$ and Lydia Avivi*2
}

\author{
Address: ${ }^{1}$ Department of Urology, Sheba Medical Center, Tel-Hashomer 52621, Israel and ${ }^{2}$ Department of Human Molecular Genetics and \\ Biochemistry, Sackler School of Medicine, Tel Aviv University, Tel Aviv 69978, Israel \\ Email: Zohar A Dotan - Zohar.Dotan@sheba.health.gov.il; Aviva Dotan - dotan-a@013.net; Jacob Ramon - Jacob.Ramon@sheba.health.gov.il; \\ Lydia Avivi* - lydia@post.tau.ac.il \\ * Corresponding author
}

Published: 25 December 2008

BMC Cancer 2008, 8:390 doi:10.1 |86/|47|-2407-8-390
Received: 29 July 2008

Accepted: 25 December 2008

This article is available from: http://www.biomedcentral.com/I47I-2407/8/390

(C) 2008 Dotan et al; licensee BioMed Central Ltd.

This is an Open Access article distributed under the terms of the Creative Commons Attribution License (http://creativecommons.org/licenses/by/2.0), which permits unrestricted use, distribution, and reproduction in any medium, provided the original work is properly cited.

\begin{abstract}
Background: Allelic counterparts of biallelically expressed genes display an epigenetic symmetry normally manifested by synchronous replication, different from genes subjected to monoallelic expression, which normally are characterized by an asynchronous mode of replication (well exemplified by the SNRPN imprinted locus). Malignancy was documented to be associated with gross modifications in the inherent replication-timing coordination between allelic counterparts of imprinted genes as well as of biallelically expressed loci. The cancer-related allelic replication timing aberrations are non-disease specific and appear in peripheral blood cells of cancer patients, including those with solid tumors. As such they offer potential blood markers for non-invasive cancer test. The present study was aimed to gain some insight into the mechanism leading to the replication timing alterations of genes in blood lymphocytes of cancer patients.
\end{abstract}

Methods: Peripheral blood samples derived from patients with prostate cancer were chosen to represent the cancerous status, and samples taken from patients with no cancer but with benign prostate hyperplasia were used to portray the normal status. Fluorescence In Situ Hybridization (FISH) replication assay, applied to phytohemagglutinin (PHA)-stimulated blood lymphocytes, was used to evaluate the temporal order (either synchronous or asynchronous) of genes in the patients' cells.

Results: We demonstrated that: (i) the aberrant epigenetic profile, as delineated by the cancer status, is a reversible modification, evidenced by our ability to restore the normal patterns of replication in three unrelated loci (CENI5, SNRPN and RBI) by introducing an archetypical demethylating agent, 5-azacytidine; (ii) following the rehabilitating effect of demethylation, an imprinted gene (SNRPN) retains its original parental imprint; and (iii) the choice of an allele between early or late replication in the aberrant asynchronous replication, delineated by the cancer status, is not random but is independent of the parental origin.

Conclusion: The non-disease specific aberrant epigenetic profile displayed in peripheral blood cells of patients with a solid tumour (unlike genetic aberrations) can be reversed, by an epigenetic drug applied in vitro, to the normal. It appears that the cancerous status differentiates between two allelic counterparts in a non-random manner, but independent of the parental origin 


\section{Background}

The fundamentals of Mendelian genetics lead to the assumption that genes of the parental genomes in mammals keep a functional symmetry: the two alleles function or shut off concomitantly in what is called biallelic expression. However, a subset of the genes is subjected to allelespecific expression (monoallelic expression), in which only one allele retains expression capability while its counterpart is silent $[1,2]$. Monoallelically expressed genes include imprinted genes [3-5], X-linked genes subjected in female cells to X-chromosome inactivation $[6,7]$, and genes displaying allelic exclusion $[8,9]$.

The functional asymmetry of alleles of an imprinted gene depends upon the parental origin of the allele - whether maternal or paternal. It is established during germ-cell development into sperm or eggs, and after fertilization each allele maintains its parental imprint, which segregates almost unchanged in the developing organism [5].

In contrast to the process of imprinting, in the processes of X-inactivation and allelic exclusion, the choice of an allele to be activated or silenced is not associated with parental origin. In the X-inactivation and allelic exclusion processes the functional capability or incapability is determined in a kind of stochastic selection by an as yet unknown selection in each individual cell: one allele stays potentially active and its partner becomes incapable of expressing itself [reviewed in [10]]. This pattern is normally maintained in a clonally-dependent manner throughout cell proliferation, enabling each tissue to carry a potentially active paternal allele in some cells and a potentially active maternal allele in other cells, the frequencies of the two cell types usually deviate from random; in some cases most of the cells (of a given tissue) carry an active maternal allele while in others most of the cells (of the very same tissue) display an active paternal allele, giving rise to a non-random pattern but independent of the parental origin $[6,7,11-14]$.

Whatever the mechanisms involved in the maintenance and selection of an allele for allele-specific expression, the functional asymmetry of monoallelically expressed genes results from the two alleles maintaining different epigenetic profiles, in which asynchronous DNA replication, similar to differential DNA methylation, plays a decisive role [reviewed in [12]].

The method of choice for evaluating the temporal order of allelic replication is the fluorescence in situ hybridization (FISH) replication assay [11,15-18]. This assay was first developed to confirm and reinstate previous observations that two homologous counterparts usually replicate concomitantly, and to demonstrate unequivocally that the two alleles of a biallelically expressed gene replicate syn- chronously, early in cells of expression and late in unexpressed cells [19]. Using this assay an asynchronous pattern of allelic replication - early replication of the potentially active allele and late replication of the silent one - was shown, not necessarily in the cells of expression, for all known types of monoallelically expressed genes: (i) imprinted genes [20-26], (ii) genes subjected to $\mathrm{X}$-chromosome inactivation [27-29], and (iii) genes undergoing allelic exclusion $[11,13,15,30,31]$.

We reported previously that imprinted genes lose their characteristic epigenetic-asymmetry, as reflected in loss of asynchronous replication, in peripheral blood lymphocytes of patients with a solid tumor such as renal cell carcinoma [25] or prostate cancer [26]. This is in accord with studies documenting loss of the allele-differential methylation characterizing imprinted genes, a phenomenon often referred to as "loss of imprinting" (LOI) in peripheral blood lymphocytes of patients with a solid tumor such as colon cancer [32,33]. Furthermore, classical biallelically expressed genes, exemplified by RB1, TP53, $A M L 1$ and C-MYC, which normally display a synchronous mode of allelic replication, yet in peripheral blood lymphocytes of patients with a solid tumor, such as renal cell carcinoma [25] or prostate cancer [26], exhibit an asynchronous pattern of replication similar to that characterizing normally monoallelically expressed genes. Even satellite chromosome-specific sequences (pericentromeric non-coding DNA arrays), which normally display synchrony in replication of homologous counterparts, similar to biallelically expressed genes, change their inherent replication mode and replicate asynchronously in lymphocytes of patients with cancer, including ovarian [34], hematological [35] and prostate cancers [26]. Considering that biallelically expressed genes in cells of cancer patients, similar to imprinted genes, are subjected to the global epigenetic disequilibrium associated with tumorigenesis [36], these replication alterations are inevitable. The feasibility to observe a cancer-linked marker in peripheral blood cells of cancer patients would be of immense value in cancer diagnosis and therapy [37], especially if it is based on DNA itself rather than on a DNA product.

The present study was aimed to gain some insight into the process leading to the replication timing alterations of genes in the blood lymphocytes of cancer patients. Specifically, we checked: (i) if the cancer-related loss of asynchronous replication of an imprinted gene, and "gain" of asynchrony of loci that normally replicate synchronously are linked to aberrant methylation; and (ii) whether the choice of an allele for early or late replication in cancerrelated asynchronous replication is random, dependent of the parental origin or non-random but independent of the parental origin. 


\section{Methods \\ Study subjects}

Forty-four male urology patients were included in the study, 22 with prostate cancer (CAP), and 22 with no cancer but with benign prostate hyperplasia (BPH). Diagnoses were based on histological examination of tissues removed from the prostate gland by surgery or biopsy. The study also included two healthy family members, the wife (designated $\mathrm{K} 1$ ) and son (designated $\mathrm{K} 2$ ) of one of the non-cancer (BPH) patients (designated $\mathrm{K}$ ). The 44 patients and the two family members of patient $\mathrm{K}$ had normal karyotypes, based on G-banded metaphase spreads.

\section{Lymphocyte cultures}

Each subject donated $5 \mathrm{ml}$ of peripheral blood prior to an invasive diagnostic procedure (surgery or biopsy), or medical treatment (hormonal, radiation, or chemotherapy). Cell cultures of PHA-stimulated lymphocytes were set up according to the standard protocol used for routine karyotype assays described previously [26]. Briefly, blood samples were cultured in F10 medium containing 20\% fetal calf serum (FCS), 3\% phytohemagglutinin (PHA), $0.2 \%$ heparin, and $1 \%$ antibiotics. Six of the 22 samples derived from the cancer (CAP) patients (designated C1C6) and six of the 22 samples obtained from the non-cancer (BPH) patients (designated B1-B6) were also cultured in the presence of $10^{-7} \mathrm{M}$ 5-azacytidine (AZA; Sigma Chemicals, St. Louis, MO. USA), added to the other ingredients of the medium. Cultures were incubated at $37^{\circ} \mathrm{C}$ for $72 \mathrm{~h}$, colchicine (final concentration of $0.1 \mu \mathrm{g} / \mathrm{ml}$ ) was added for $1 \mathrm{~h}$, and hypotonic treatment $(0.075 \mathrm{M} \mathrm{KCl}$ at $37^{\circ} \mathrm{C}$ for $15 \mathrm{~min}$ ) and four washes were carried out, each with a fresh cold fixation solution (3:1 methanol: acetic acid solution). The cell suspensions in the fixative solution were stored at $-20^{\circ} \mathrm{C}$ until analysis by FISH.

\section{DNA probes}

Three directly labeled commercial probes obtained from Vysis Inc. (Downers Grove, IL, USA) were used: (i) the SNRPN probe (32-190004), which identifies the imprinted SNRPN gene, located on the long arm of chromosome 15 (15q11-q13, within the Prader-Willi/Angelman syndrome imprinted region) adjacent to the centromere; (ii) the RB1 Probe (32-190001), which identifies the retinoblastoma tumor suppressor gene, a classical biallelically expressed gene [38]; and (iii) the CEN15 probe (32-130015), which identifies the pericentromeric region of chromosome 15 (CEN15). CEN15 was considered appropriate because it faithfully mimics the replication mode of a biallelically expressed locus, it has a size polymorphism that enables identification of each specific allelic counterpart in informative cells, and it is located in the vicinity of the SNRPN, whose replication status tells the parental origin of the chromosome $[20,23]$, enabling easy determination of the parental origin of each CEN15 morph (for details see Fig. 1).

\section{Probe application}

Applying one-color FISH, each of the 44 samples derived from the urology patients was hybridized individually with the SNRPN probe and the CEN15 probe. In addition, each of six samples from the BPH group of patients (cases B1-B6) and each of six samples from the CAP group (cases $\mathrm{C} 1-\mathrm{C} 6$ ), was hybridized with the RB1 probe too.

Of the 44 samples, 11 were polymorphic for a large CEN15 marker: five from the BPH group (including patient $\mathrm{K}$ ) and six from the CAP group. These 11 samples and the sample from the healthy son (K2) of patient $\mathrm{K}$ were all hybridized concomitantly with two probes, SNRPN and CEN15 (two-color FISH). The sample of the wife of patient K (K1) was hybridized with the CEN15 probe only and displayed two normal, equal-sized CEN15 signals, verifying that the large CEN15 marker of K2 (Fig. 1) was of paternal origin.

\section{In-situ hybridization}

We followed a protocol previously described [26]. Cells were dropped onto two-well slides (Insitus Biotechnolo-

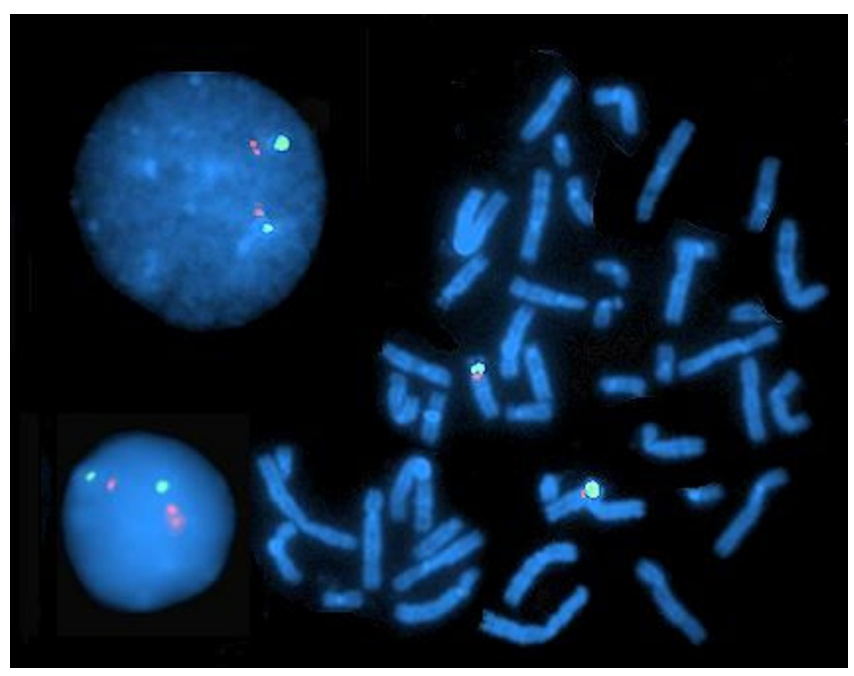

Figure I

Cells of a healthy (cancer free) individual (case K2) heterozygous for the large CEN 15 marker (derived from the paternal parent) after two-color FISH with SNRPN (red signals) and CENI5 (green signals). Left, two interphase cells representing SD cells for SNRPN and SS cells for CEN15. Right, cell at metaphase with chromosome15 homologues identified by the CENI5 and SNRPN signals. Note the difference in signal size between the two CEN/5 counterparts in each cell, and the association of the replicated SNRPN locus (doublet; D-signal) in both interphase cells with the large CEN/5. 
gies, Albuquerque, NM, USA) with no pretreatment. Five $\mu \mathrm{l}$ of the probe solution, diluted in D003 (SNRPN and $R B 1)$ or D001 (CEN15) Ingen's DenHyb hybridization solution (Insitus Biotechnologies), were placed on the targeted area of the sample slides, covered with a $12 \mathrm{~mm}$ round silianized coverslip (Insitus Biotechnologies), and sealed with rubber cement. The slides were placed in a micro-heating system (Vysis Inc.), programmed first for 6 min denaturation at $76^{\circ} \mathrm{C}$ and then for 18 hours hybridization at $37^{\circ} \mathrm{C}$.

\section{Post-hybridization treatments}

Following removal of the coverslips, post-hybridization washes consisted of immersing the slides for $2 \mathrm{~min}$ in a solution of $0.4 \times \mathrm{SSC}$ pH 7.0 with $0.3 \% \mathrm{NP} 40$ at $72{ }^{\circ} \mathrm{C}$, followed by $2 \mathrm{~min}$ in $2 \times$ SSC with $0.1 \% \mathrm{NP} 40$ at room temperature in a shaking water bath. After brief drying, the slides were covered with an antifade solution containing 4,6-diamidino-2-phenylindole (DAPI; $3 \mu \mathrm{g} / \mathrm{ml}$; Vector Laboratories, Inc., Burlingame, CA, USA), coated with glass coverslips, and stored at $-20^{\circ} \mathrm{C}$ until analyzed.

\section{Cytogenetic evaluation}

Slides were analyzed blindly on an Olympus BH2 fluorescent microscope equipped with a triple band-pass filter (Chroma Technology, Brattleboro, VT, USA). The FISH replication assay was used to estimate the replication status of each allelic region as described previously [26]. Accordingly, the structure of the fluorescent signal of each identified region was noted: either singlet $(\mathrm{S})$, denoting a non-replicated sequence, or doublet (D), disclosing a replicated sequence. Thus, in a population of replicating cells, the frequency of cells exhibiting an "S" signal for one allele and a "D" signal for the other (SD cells), out of the total population of cells with two fluorescent signals, represented the level of asynchrony in the replication timing of the identified alleles. High SD-cell frequency indicated an asynchronous mode of replication, and low frequency a synchronous mode $[16,17,20]$.

For estimation of the frequency of SD cells at least 100 cells with two clear signals were scored from each sample, for each treatment, for each locus, following one-color FISH with the relevant probe. To differentiate a specific CEN15 or SNRPN allele from its allelic counterpart based on the size-polymorphism of the CEN15 fluorescent signal, at least 200 SD cells for the locus in question were scored from each informative sample; for CEN15 differentiation one-color FISH (with the CEN15 probe) and for SNRPN differentiation two-color FISH (with the CEN15 and the SNRPN probes) were applied.

\section{Statistical method}

The statistical significance of the differences between two cell populations was determined using the two-tailed Stu- dent's t-test (Microsoft Excel) and a P value $<0.01$ was considered statistical significant.

\section{Ethical basis}

Informed consent was obtained from each individual examined, and the Ethics Committee of the Sheba Medical Center approved the study.

\section{Results \\ Replication timing alterations of SNRPN and CEN I 5 in cells of cancer patients are readjusted in the presence of 5 - azacytidine (AZA, a methylation-blocking agent)}

The frequency of SD cells (see 'Cytogenetic evaluation' in Materials and Methods) for SNRPN was high in cells of the cancer-free urology patients, as expected for an imprinted region in normal samples. However, this very same locus in the samples of the cancer patients revealed low SD values, significantly lower $\left(\mathrm{P}<10^{-11}\right)$ than the expected values (Fig. 2; Table 1). In addition, the CEN15 alleles, which normally replicate synchronously, as seen here in the cells of the non-cancer patients (Fig. 2a), replicated highly asynchronously in the cells of the cancer patients, similar $(\mathrm{P}>0.30)$ to the SNRPN in the cells of cancer-free patients (Fig. 2; Table 1). Thus, the cells of the cancer patients exhibited an abnormal mode of allelic replication: low SD values for SNRPN, which were significantly lower $\left(\mathrm{P}<10^{-11}\right)$ than the SD values obtained in the same samples for the CEN15 locus (Fig. 2b), and only slightly higher $(P<0.02)$ than the low $S D$ value shown for CEN15 in the non-cancer samples (Fig. 2; Table 1). At the same time, the cells of the cancer-free urology patients exhibited the normal pattern of replication: high SD values for SNRPN and significantly lower $\left(10^{-12}\right)$ values for CEN15 (Fig. 2a).

The abnormal SD values for SNRPN and CEN15 in the cells of the cancer patients were shifted toward normal in the presence of AZA, a methylation-blocking agent (Fig. $3 \mathrm{~b}$ and $3 \mathrm{~d})$. In contrast, the samples of the non-cancer patients were not affected by AZA (Fig. 3a and 3c), evidenced by the lack of difference, in the presence of AZA, between the cancer cases and the non-cancer cases in the SD values for SNRPN as well as for CEN15 (Fig. 3).

It is noteworthy that CEN15 mimics the replication timing of RB1: (i) low SD values in cells of cancer-free patients, both with and without AZA; (ii) high SD values in the cells of the cancer patients, similar to those obtained for an imprinted region in normal cells; and (iii) a decrease in the abnormal (high) SD values in the cells of the cancer patients to normal low levels in the presence of AZA (Fig. 3c-f). 

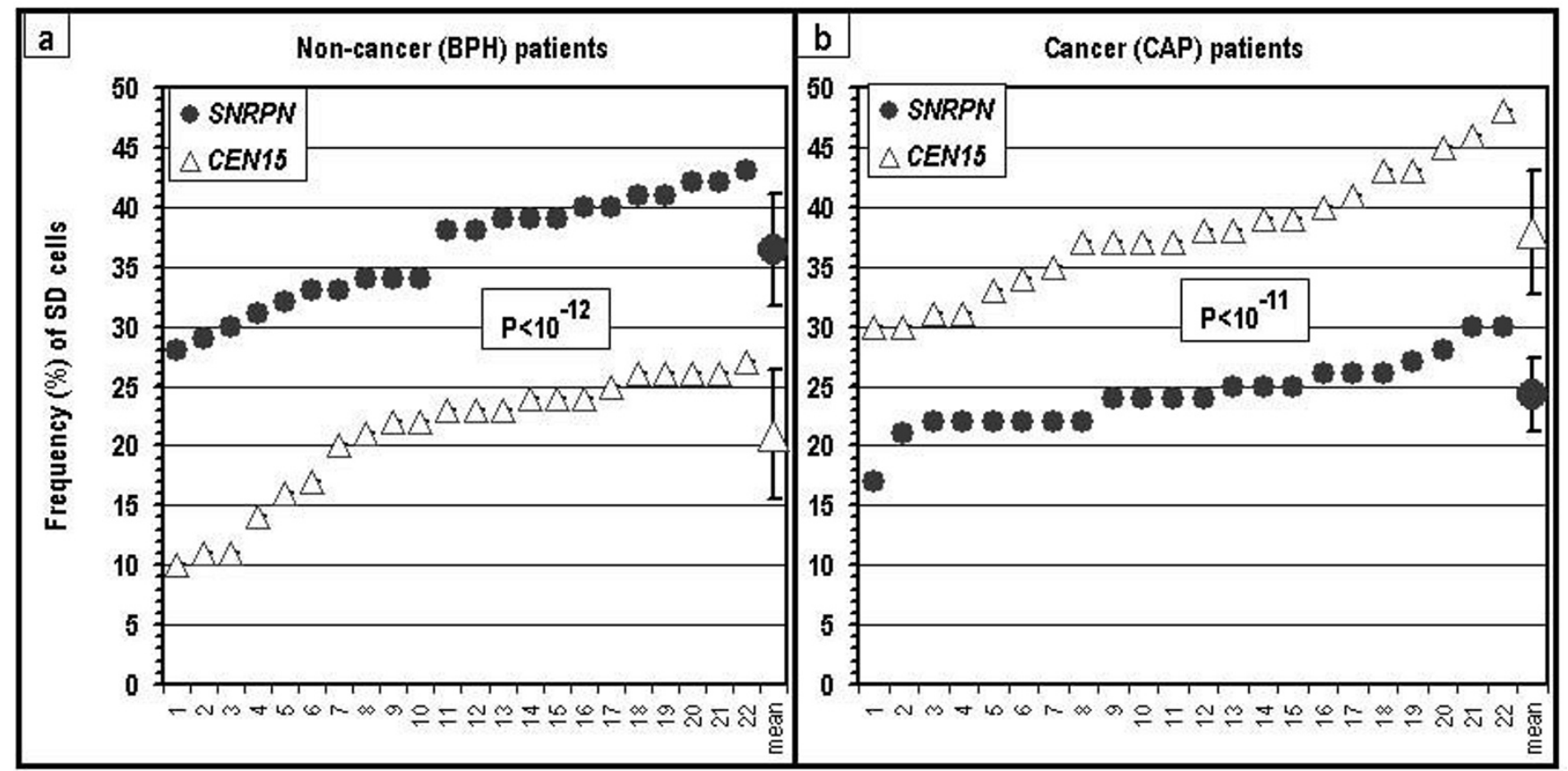

\section{Figure 2}

SD values for SNRPN and CENI5 in cells of two groups of urology patients: (a) patients free of cancer (BPH); and (b) cancer patients (CAP). The values in each frame for each locus are presented in increasing order. $P$ - the level of significance of the differences between the SNRPN and the CENI 5 loci within a group of patients.

The loss of the asynchronous pattern of SNRPN replication in cells of cancer patients is not accompanied by randomization of the early and late replicating alleles Following one-color FISH with the CEN15 probe, 11 of the 44 samples studied were heterozygous for CEN15 size: six derived from cancer (CAP) patients (designated $\mathrm{Y}, \mathrm{J}, \mathrm{A}$, $\mathrm{C}, \mathrm{B}$, and $\mathrm{S}$ ), and five from non-cancer (BPH) patients (designated G, V, R, Z, and K). Each displayed at both interphase and metaphase one large and one small CEN15 signal (illustrated in Fig. 1). The son of patient K was a young healthy man (K2) who happened to be heterozygous for a large CEN15 marker (Fig. 1), similar to his

Table I: Level of significance of the differences $(P)$ in SD values for the designated loci between samples of patients free of cancer (BPH) and cancer patients (CAP).

\begin{tabular}{ccc}
\hline & $\begin{array}{r}\text { BPH SNRPN } \\
(36.4 \pm 4.7 \%)\end{array}$ & $\begin{array}{c}\text { BPH CENI5 } \\
(20.9 \pm 5.3 \%)\end{array}$ \\
\hline $\begin{array}{c}\text { CAP SNRPN } \\
(24.3 \pm 3.0 \%)\end{array}$ & $\mathrm{P}<10^{-11}$ & $\mathrm{P}<0.02$ \\
\hline $\begin{array}{c}\text { CAP CEN } 15 \\
(37.8 \pm 5.1 \%)\end{array}$ & $\mathrm{P}>0.30$ & $\mathrm{P}<10^{-12}$ \\
\hline
\end{tabular}

In parentheses are the mean SD frequency (\%) and the standard deviation value for the group of patients for the particular locus. Each group contained 22 cases (the compared values are presented in Figure 2). father $(\mathrm{K})$; his mother (K1) was homozygous for two small CEN15 markers (data not shown).

Using two-color FISH to identify the CEN15 and the SNRPN in the same cell, we examined the population of SD cells for SNRPN in the samples heterozygous for the large CEN15 marker. The early replicating SNRPN allele was not randomly distributed between the two chromosome-15s in either the informative (heterozygous) samples derived from non-cancer cases (Fig. 4a) or those derived from the informative cancer cases (Fig. 4c). Specifically, in the samples of the non-cancer BPH cases $(G, R$ and $\mathrm{K}$ ), in the $\mathrm{K} 2$ sample, and in one sample of a cancer (CAP) case (J), the early replicating SNRPN allele was located in more than $70 \%$ of SD cells on the chromosome carrying a large CEN15 marker. On the other hand, in samples $\mathrm{V}$ and $\mathrm{Z}$ derived from non-cancer patients, as well as samples $\mathrm{Y}, \mathrm{A}$, and $\mathrm{C}$ derived from cancer patients, the early replicating $S N R P N$ allele was found in more than $75 \%$ of SD cells on the chromosome identified by a small CEN15 marker (Fig. 4a and 4c). This clearly showed that the relaxation in the asynchronous replication of SNRPN (reduced SD-cell frequency) that characterizes samples of cancer patients was not accompanied by randomization of the early and late replicating alleles. 


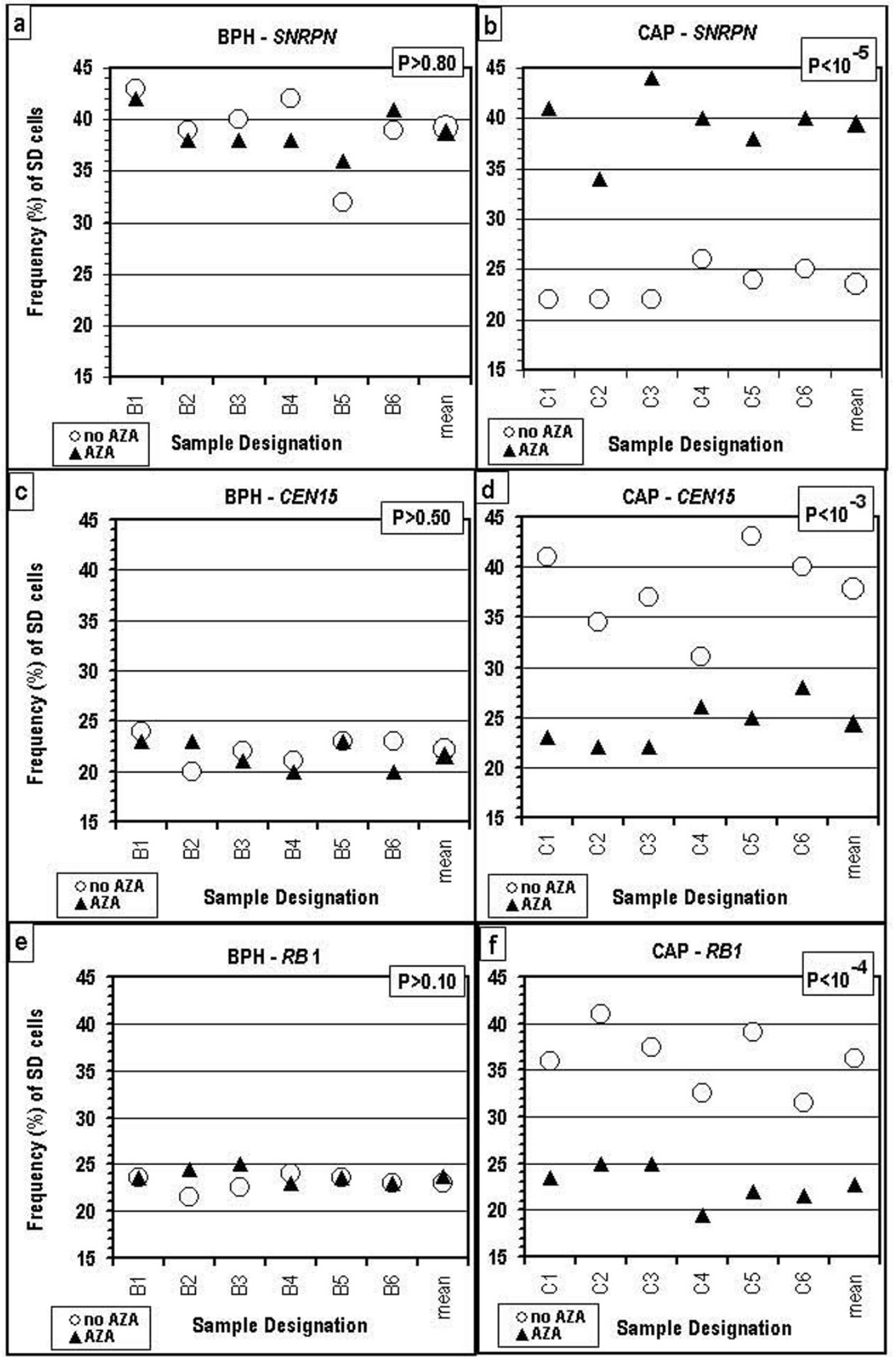

\section{Figure 3}

SD values for the SNRPN, CENI5 and RBI loci, in the absence ( $\bigcirc)$ and in the presence (A) of AZA. (a), (c) and (e) values of patients free of cancer (BPH cases); (b), (d) and ( $f$ ) values of urology cancer patients (CAP cases). $P$ - the level of significance of the differences between corresponding values obtained in the presence and absence of AZA. 


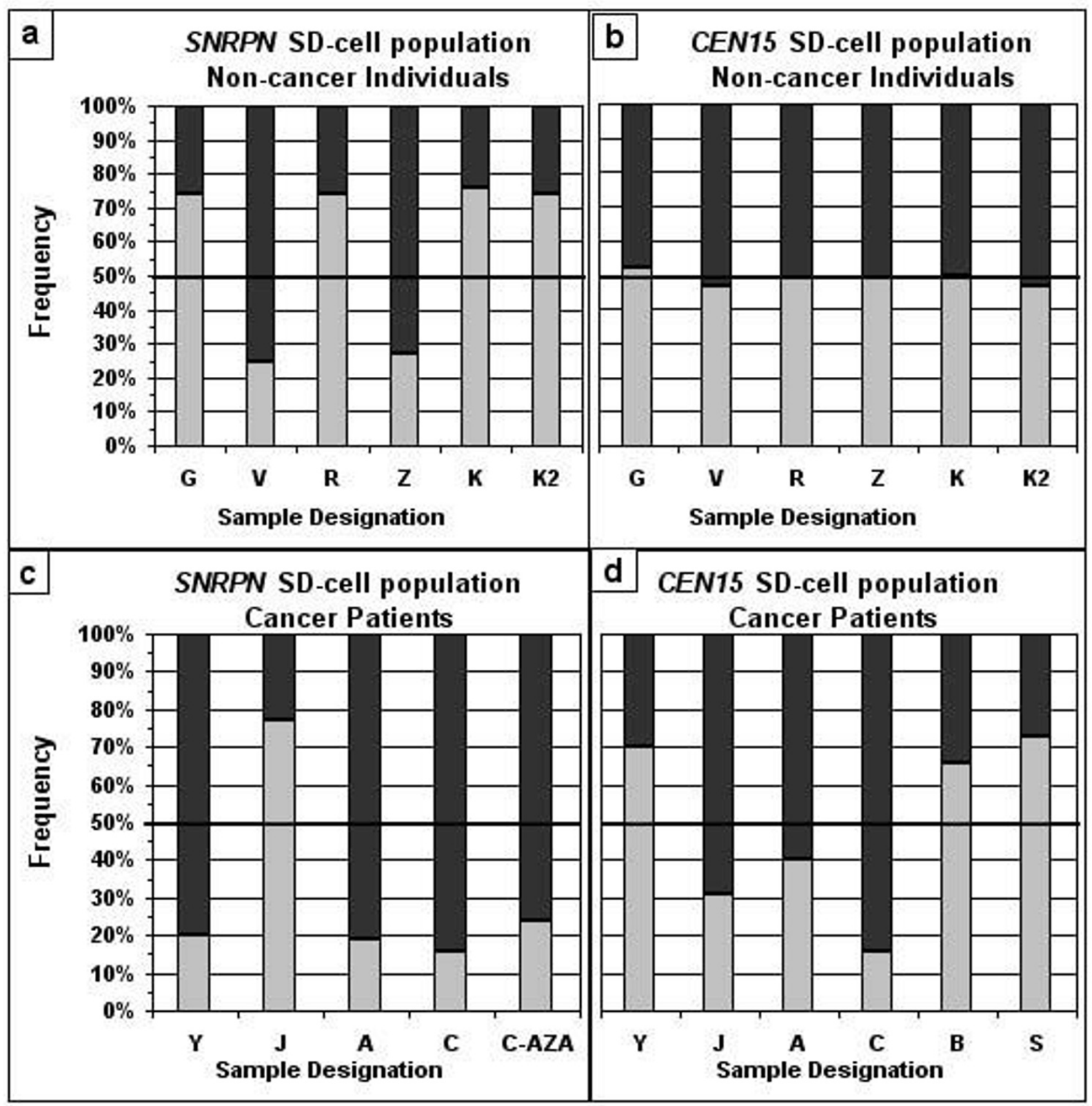

\section{Large $\square$ Small}

\section{Figure 4}

Characterization of the SD-cell populations for SNRPN and CEN/ 5 in cell samples of individuals heterozygous for the CENI5 size, showing one large and one small CEN/5 marker. Light bars show the portion (\%) of the relevant SD-cell population in which the replicated region (D-signal) is associated with the large CEN/ 5 marker, and dark bars show the SD-cell portion in which the D-signal is associated with the small CEN/5 marker. (a) and (b) samples of cases free of cancer (K2 was from a healthy young man, the son of K); (c) and (d) samples of cancer patients; the last bar in frame (c) is a sample of cancer patient $C$ (case $C 5$ in Fig. 3) grown in the presence of AZA; at least 200 SD cells were scored from each sample for each assay. 
Moreover, the rehabilitating effect of AZA, which restored the normal high SNRPN SD values in cancer samples (Fig. $3 \mathrm{~b})$, reinstated the early replicating $S N R P N$ allele on the same chromosomal counterpart at which the early replicating allele was located in the absence of the drug (apparently the paternal chromosome). This was demonstrated by cancer case C: in most of the SD cell population for $S N R P N$ the early replicating allele was on the chromosome identified by a small CEN15 marker both before and after AZA application (see the two last bars in Fig. 4c).

Worthy of notice that $\mathrm{K} 2$ is of particular interest here because the parental origin (paternal) of the large CEN15 marker was known, and the early replicating SNRPN allele was indeed associated with the paternal chromosome (see last two bars in Fig. 4a). Moreover, the results of the father (K) and the son (K2) confirmed previous findings [20,23] that, in informative CEN15 cases, the replication status of the SNRPN locus enables identification of parental origin of chromosome 15 with no need for family studies, which are usually complicated, especially in elderly subjects.

\section{The allelic choice for an asynchronous pattern of replication for CENI 5 in cells of cancer patients is a non- random event, but is not associated with a parent-of- origin-dependent effect}

Next, we undertook to determine whether the choice of an allele in the cancer-related process of allele-specific replication is a random event. Using the informative (heterozygous) CEN15 samples, we analyzed the SD-cell population for CEN15 and found that the early replicating CEN15 allele in the cancer samples is not selected at random. Specifically, in three out of the six cancer patients $(\mathrm{Y}$, $\mathrm{B}$, and $\mathrm{S}$ ), the early replicating allele was the large one, showing the D-signal in $65 \%$ or more of SD cells for CEN15. In the other three cases (J, A, and C), the early replicating allele appeared to be the small one, showing the D-signal in $60 \%$ or more of the SD-cells for CEN15 (Fig. 4d).

It is noteworthy that in the occasional SD-cell population for CEN15 (low SD frequency) that appeared in the samples of non-cancer individuals, the selection for an early or late replicating CEN15 allele appeared to occur at random. This was evident from the equal frequencies $(50 \%$ each) of cells with an early replicating large allele and an early replicating small allele observed in the SD-cell population for CEN15, in each of the six informative samples of the non-cancer individuals (Fig. 4b). These small populations of SD cells (usually found in synchronously replicating regions) differ from the large SD-cell population characterizing asynchronous replication and most likely result from background noise.
Finally, we checked whether the non-random selection of an early- or late- replicating CEN15 allele in the cancer samples is a parent-of-origin-dependent process. Apparently it is not. Proof comes from the lack of coordination in the replication status between the CEN15-allele and the $S N R P N$-allele assigned to the same homologue. The early replicating CEN15 allele in cancer cases A and C resided on the same homologous chromosome as the early replicating SNRPN allele. On the other hand, in cancer cases $\mathrm{Y}$ and J, the early replicating CEN15 and SNRPN alleles were assigned to different homologues (bars $\mathrm{Y}, \mathrm{J}, \mathrm{A}$, and $\mathrm{C}$ in Fig. $4 \mathrm{c}$ and $4 \mathrm{~d}$ ). This indicates that the cancer-related asynchronous replication in the CEN15 region, while clearly not random, is guided by a mechanism other than a parent-of-origin-dependent one.

\section{Discussion}

The asynchronous pattern of replication of the SNRPNimprinted locus, consisting of early replication of the paternal allele (exemplified here in cells of the healthy son (K2) of a non-cancer patient) is in accord with the large amount of data documenting an allele-specific parent-of-origin replication mode for this locus in normal human cells [20-24]. The SNRPN pattern of replication differs significantly from the normal synchronous pattern observed for biallelically expressed genes $[19,25,26,35,39]$, shown here in cells of the non-cancer patients by a non-transcribed locus - the chromosome-15 pericentromeric DNA array (CEN15).

However, in PHA-stimulated peripheral blood lymphocytes of the cancer patients, the SNRPN gene exhibited a relaxation, almost a loss, leaving only remnants of its characteristic asynchronous pattern of replication. This confirmed our earlier finding that blood cells of patients with urological cancers display relaxation in the asynchronous pattern of allelic replication characterizing imprinted loci $[25,26]$. It is noteworthy that loss of asynchronous replication of SNRPN was used to confirm lack of imprinting in cells of individuals carrying uniparental disomy for the SNRPN locus $[21,23,24,40]$. In addition to loss of the asynchronous replication of the imprinted locus, the blood lymphocytes of the cancer patients studied here exhibited extreme changes in replication timing of the CEN15 locus, which was asynchronous. These findings confirm our previous findings of cancer-related, nonlocus specific replication timing alterations of loci (that normally replicate synchronously) in blood lymphocytes of patients with a solid tumor (see Introduction). Thus, an aberrant epigenetic profile is seen in blood cells of cancer patients, one marked by non-locus specific asynchronous replication of normally biallelically expressed loci and synchronous replication of imprinted genes. 
Yet, the aberrant epigenetic profile in blood cells of the cancer patients was reverted to normal in the presence of AZA, a classical methylation blocking agent, linking the global cancer-related replication timing alterations to methylation capacity (discussed later). These results are in accord with findings that an AZA analog, 5-aza-2'-deoxycytidine, which mimics AZA in its demethylation activities, restored the normal imprinting in cancer cells exhibiting LOI [41,42]. Here, we show that AZA reinstated the asynchronous replication of SNRPN in cells of the cancer patients by re-establishing the advanced replication of the normally early replicating (paternal) allele. This suggests that the cancer-related loss of asynchronous replication of SNRPN observed here resulted from delayed replication (due to cancer-mediated hypermethylation) of the normally early replicating paternal allele, rather than advanced replication of the normally late replicating maternal allele. It cannot be ruled out, however, that the loss of SNRPN asynchronous replication resulted from advanced replication of the late replicating (maternal) allele. In fact, classical reports of LOI documented that cancer related relaxation of imprinting may arise either from activation of the normally silent allele or from inactivation of the normally expressed allele $[36,43]$.

CEN15-replication behaviour, in normal situations as well as in reaction to cancer status and to the methylation blocking agent, completely mimics a biallelically expressed locus. This is shown here by the similarity between the CEN15 and the retinoblastoma gene RB1: the first known tumor suppressor gene, also the first to show an epigenetic inactivation - hypermethylation - rather than a genetic inactivation in a tumor suppressor gene, and to disclose that this inactivation was linked to an allele-specific event [38]. It is therefore reasonable to assume that CEN15 fully characterizes biallelically expressed loci; and, assuming that SNRPN reliably represents an imprinted locus, it appears that LOI is only one aspect of a much broader cancer-related epigenetic alteration, namely, loss of the inherent coordination between alleles. This alteration is neither locus- nor disease-specific, and is erased in the presence of AZA-like methylation-blocking agents. The alteration was evidenced here by loss of replication timing properties of three unrelated loci in blood cells of prostate cancer patients.

The FISH replication assay as used here (avoiding S-phase cells labeling) is a simple and reliable method for replication timing analysis. First, we show here that in the normal samples, it repeats results obtained by others in labeled S-phase cells $[17,18,20-24]$. Second, it is evident that the considerably low frequency of SD cells for SNRPN characterizing the cancer cases cannot be attributed to shortening of the duration of the S-phase since at the same time these same samples revealed a significant increase in the frequency of SD cells for CEN15 and RB1. Similarly, while an increase in the S-phase duration may explain the increase in the frequency of SD cells for CEN15 and RB1, it fails to explain the dramatic decrease in the frequency of SD observed for the SNRPN locus. Furthermore, because FISH uses single cells rather than bulks of DNA, it appears to be especially sensitive for differentiating between the synchronous and asynchronous modes of allelic replication. In addition, the assay estimates only stages prior to or after termination of the whole replication process of each counterpart of a tested locus, rather than pooled Sphase cells, some of which are trapped in the course of the replication process of the tested locus $[15,17,18]$.

Using cell samples of cancer patients that are heterozygous for a size polymorphism at the CEN15 region enabled us to show that the selection of an allele for early or late replicating in the cancer-related asynchronous replication was not random; in each sample, most of the informative cells revealed one specific allele exhibiting early replication, either the small or the large one. This non-random choice was not dependent on the parental origin of CEN15, because in some cases the early replicating CEN15 allele was assigned to the same chromosome on which the early replicating SNRPN locus resided (paternal chromosome), and in others on the chromosome carrying the late replicating SNRPN locus (maternal chromosome). This suggests that the selection of a CEN15 allele for allele-specific replication in the cells of cancer patients is similar to the choice of an early (active) or late (inactive) replicating chromosome in the process of $\mathrm{X}$ inactivation [44,45]; furthermore, it resembles the selection of the early (active) allele in the process of allelic exclusion $[11,15]$. Neither mechanism is parent-of-origindependent, but both (one made on the chromosome level and the other on the allelic level) ensure that the selected homolog (allele) for early (or late) replication passes the information from one generation to the next in a cell lineage. However, the mechanism that renders the two copies of a locus different from one another is unknown.

It was proposed that a normally existing variation in the accumulation of long interspersed nuclear elements (LINE)-1 facilitates differentiation between homologous counterparts for X-inactivation [46], as well as for the allele-specific expression of autosomal genes [47]. Since considerably high densities of LINE-1 repeats also appear in various autosomal regions not known to exhibit allelic differences in gene expression, the role of LINE-1 repeats in the mechanism initiating allelic functional asymmetry seemed doubtful [47]. However, recent data showing that monoallelically expressed genes are more widespread on autosomes than expected [48] may strengthen the LINE hypothesis, raising the possibility that the cancer status takes advantage of such a variation. Furthermore, it seems 
that those recently discovered autosomal monoallelically expressed genes retain an inherent functional plasticity with regard to monoallelical and biallelical expression $[2,48]$, which may facilitate the shifting from one mode of expression to the other in response to malignancy.

Different nuclear positions of alleles in the interphase nucleus at the S-phase were reported to accompany allelic asymmetry $[10,12,18]$. Hence, one may speculate that the epigenetic disequilibrium linked to the cancer phenotype [36] alters the spatial DNA organization within the nucleus, positioning each of the parental sets at a different replication domain and thereby affecting the epigenetic symmetry of various genes at once.

The mechanism involved in maintenance of allele-specific replication, observed here in response to cancer, may resemble that involved in maintaining the functional asymmetry between the two homologous counterparts resulting from both X-inactivation and allelic exclusion. Both these processes are maintained by the methylation capacity of the genome $[11,49]$, similar to what we observed in the cancer-related asynchronous replication. However, the asynchronous replication acquired by the cancer-status, probably later in life (shown here for CEN15 and RB1 in cells of cancer patients), differs in the response to AZA from that hatched normally into genes at early developmental stages (exemplified here by SNRPN in cells of non-cancer patients). We show here that the former is reversed in the presence of AZA, and the latter is unaffected. Our findings are in accord with reports claiming that AZA-like drugs activate genes subjected to epigenetic silencing, particularly if the silencing occurred due to a pathological situation, making these drugs efficacious in treating cancer [50-52]. Specifically, AZA and its analogs are active only in S-phase cells, as they became incorporated (in place of cytosine) into replicating DNA. The newly formed azacytosine-containing DNA blocks methyltransferases activity [50]. As such, these drugs generates heritably demethylated DNA, and, thus, activate silent genes, shifts replication timing of various DNA sequences to early replication S-phase domains [53].

According to our results, each of the cancer patients had an allele-specific replication mode for loci that normally replicate in the classical biallelic-mode. Each of the noncancer patients showed the expected synchronous patterns of replication for each of these loci. Taken together, these results suggest that the aberrant replication mode is a response to the disease and not an inborn- or ageacquired cancer-predisposing epigenetic marker. This holds true also for the aberrant replication shown for the imprinted locus. This concept is strengthened by the fact that the non-cancer patients tested here were at an advanced age and therefore at increased risk for develop- ing cancer compared to the normal population. Hence, the allele-specific labelling, in contrast to X-inactivation and allelic exclusion, most probably occurs during the lifespan of an individual rather than at the prenatal early developmental stages. This accords with the idea that epigenetic alterations associated with modifications in methylation capacity may take place later in life as well $[50,54]$. However, it should be emphasized that the cancer-based aberrant patterns of replication are not age dependent, as they characterize young cancer patients as well as elderly ones [35].

Finally, a cancer-related, non-disease specific, aberration observed for a large number of loci in a single cell sample, achieved by low invasive means, offers a way to identify potential epigenetic biomarkers for cancer detection and disease follow up. Besides, an aberration that can be reversed to normal by an epigenetic drug applied in vitro may provide a candidate marker for cancer drug evaluation.

\section{Conclusion}

The cancer-related, non-locus specific, allelic replication timing aberration, observed in peripheral blood cells, is linked to aberrant methylation and may be reversed to normal by an epigenetic drug applied in vitro. It is analogous, although broader in manifestation, to loss of imprinting, a phenomenon widely associated with malignancy. The choice of an allele for early or late replication in the cancer-related asynchronous replication is not random but independent of the parental origin.

\section{Competing interests}

The authors declare that they have no competing interests.

\section{Authors' contributions}

ZAD participated in the design of the study, carried out most of the cytogenetic studies, performed the statistical analyses and helped to draft the manuscript. AD participated in the design of the study, carried out a part of the cytogenetic studies, and helped to draft the manuscript. JR participated in the design of the study. LA conceived the study, and participated in its design and coordination and drafted the manuscript. All authors read and approved the final manuscript.

\section{Acknowledgements}

This research was funded by the Israel Cancer Association through the Yehudit Kleinberger Memorial Foundation. The authors also thank Nava Rabin and Miriam Gotlib for their technical assistance.

\section{References}

I. Ohlsson R, Tycko B, Sapienza C: Monoallelic expression: "there can only be one". Trends Genet 1998, 14:435-438.

2. Ohlsson R: Widespread monoallelic expression. Science 2007, 3 1 8: 1077-1078. 
3. Sapienza C, Hall JG: Genetic imprinting in human disease. In The metabolic and molecular bases of inherited disease 7th edition. Edited by: Scriver CR, Beauder A L, SlyW S, Valee D. New York: McGrawHill Inc; 1995:437-458.

4. Feinberg AP: Genomic imprinting and cancer. In The genetic basis of human cancer Edited by: Vogelstein B, Kinzler KW. New York: McGraw-Hill Inc; 1998:95-I07.

5. Reik W, Walter J: Genomic imprinting: parental influence on the genome. Nat Rev Genet 2001, 2:21-32.

6. Willard HF: The sex chromosomes and $\mathbf{X}$ chromosome inactivation. In The metabolic and molecular bases of inherited disease 7th edition. Edited by: Scriver C R, Beauder AL, Sly W S, Valee D. New York: McGraw-Hill Inc; 1995:719-737.

7. Heard $E$, Clerc $P$, Avner $P: \mathbf{X}$-chromosome inactivation in mammals. Ann Rev Genet 1997, 3 I:57|-610.

8. Chess A: Expansion of the allelic exclusion principle? Science 1998, 279:2067-2068.

9. Chess A: Monoallelic expression of protocadherin genes. Nat Genet 2005, 37:120-121.

10. Yang PK, Kuroda M: Noncoding RNAs and Intranuclear positioning of monoallelic gene expression. Cell 2007, I 28:777-786.

I I. Mostoslavsky R, Singh N, Tenzen T, Goldmit M, Gabay C, Elizur S, Q $\mathrm{P}$, Reubinoff BE, Chess A, Cedar H, Bergman Y: Asynchronous replication and allelic exclusion in the immune system. Nature 200I, 4I 4:22I-225.

12. Goldmit M, Bergman Y: Monoallelic gene expression: a repertoire of recurrent themes. Immunol Rev 2004, 200:197-2 I4.

13. Gimelbrant AA, Ensminger AW, Qi P, Zucker J, Chess A: Monoallelic expression and asynchronous replication of p I 20 catenin in mouse and human cells. I Biol Chem 2005, 280: I354-1359.

14. Shykind BM: Regulation of odorant receptors: one allele at a time. Hum Mol Genet 2005, I 4:R33-R39.

15. Ensminger AW, Chess A: Coordinated replication timing of monoallelically expressed genes along human autosomes. Hum Mol Genet 2004, 1 3:651-658.

16. Boggs BA, Chinault AC: Analysis of DNA replication by fluorescence in situ hybridization. Methods 1997, I3(3):259-270.

17. Simon I, Tenzen T, Reubinoff BE, Hillman D, McCarrey JR, Cedar H: Replication of imprinted genes is established in the gametes and maintained during development. Nature 1999 , 401:929-932.

18. Gribnau J, Hochedlinger K, Hata K, Li E, Jaenisch R: Asynchronous replication timing of imprinted loci is independent of DNA methylation, but consistent with differential subnuclear localization. Genes Dev 2003, I 7:759-773.

19. Selig S, Okumura K, Ward DC, Cedar H: Delineation of DNA replication time zones by fluorescence in situ hybridization. EMBO J 1992, I I:1217-1225.

20. Kitsberg D, Selig S, Brandeis M, Simon I, Keshet I, Driscol DJ, Nicholls $\mathrm{RD}$, Cedar H: Allele-specific replication timing of imprinted gene regions. Nature 1993, 364:459-463.

21. Knoll JHM, Cheng SD, Lalande M: Allele specificity of DNA replication timing in the Angelmann/Prader-Willi syndrome imprinted chromosomal region. Nat Genet 1994, 6:4 I-46

22. Gunaratne $\mathrm{PH}$, Nakao $M$, Ledbetter $\mathrm{DH}$, Sutcliffe JS, Chinault AC Tissue-specific and allele-specific replication timing control in the imprinted human Prader-Willi syndrome region. Genes Dev 1995, 9:808-820.

23. LaSalle JM, Lalande M: Domain organization of allele-specific replication within the GABRB3 gene cluster requires a biparental I 5q I I-I3 contribution. Nat Genet 1995, 9:386-394.

24. White LM, Rogan PK, Nicholls RD, Wu BL, Korf B, Knoll JHM: Allele specific replication of $15 \mathrm{qI} \mid-\mathrm{q} / 3$ loci: a diagnostic test for uniparental disomy. Am J Hum Genet 1996, 59:423-430.

25. Dotan ZA, Dotan A, Litmanovitch T, Ravia Y, Oniasvili N, Leibovitch I, Ramon J, Avivi L: Modification in the inherent mode of allelic replication in lymphocytes of patients suffering from renal cell carcinoma: a novel genetic alteration associated with malignancy. Genes Chromosomes Cancer 2000, 27:270-277.

26. Dotan ZA, Dotan A, Ramon J, Avivi L: Altered mode of allelic replication accompanied by aneuploidy in peripheral blood lymphocytes of prostate cancer patients. Int J Cancer 2004, I | |:60-66.

27. Torchia BS, Call LM, Migeon BR: DNA replication analysis of FMRI, XIST, and factor $8 \mathrm{C}$ loci by FISH shows nontran- scribed X-linked genes replicate late. Am J Hum Genet 1994 , 55:96-104.

28. Boggs BA, Chinault AC: Analysis of the replication timing properties of human $\mathbf{X}$-chromosomal loci by fluorescence in-situ hybridization. Proc Natl Acad Sci USA 1994, 91:6083-6087.

29. Yeshaya J, Shalgi R, Shohat M, Avivi L: FISH-detected delay in replication timing of mutated FMRI alleles on both active and inactive X-chromosomes. Hum Genet 1999, I 05:86-97.

30. Simom I, Tenzen T, Mostosslavsky R, Fibach E, Lande L, Milot E, Gribnau J, Grosveld F, Fraser P, Cedar H: Developmental regulation of DNA replication timing at the human $\beta$ globin locus. EMBO / 2001, 20:6150-6157.

31. Chess A, Simon I, Cedar H, Axel R: Allelic inactivation regulates olfactory receptor gene expression. Cell 1994, 78:823-834.

32. Cui H, Horon IL, Ohlsson R, Hamilton SR, Feinberg AP: Loss of imprinting in normal tissue of colorectal cancer patients with microsatellite instability. Nat Med 1998, 4: | 276-|280.

33. Cui H, Cruz-Correa M, Giardiello FM, Hutcheon DF, Kafonek DR Brandenburg S, Wu Y, He X, Powe NR, Feinberg AP: Loss of IGF2 imprinting: a potential marker of colorectal cancer risk. Science 2003, 299: I753-I755.

34. Litmanovitch T, Altaras MM, Dotan A, Avivi L: Asynchronous replication of homologous $\alpha$-satellite DNA loci in man is associated with non-disjunction. Cytogenet Cell Genet 1998, 81:26-35.

35. Korenstein-Ilan A, Amiel A, Lalezari S, Lishner M, Avivi L: Allele specific replication associated with aneuploidy in blood cells of patients with hematological malignancies. Cancer Genet Cytogenet 2002, 139:97-103.

36. Feinberg $A P$, Ohlsson $R$, Henikoff $S$ : The epigenetic progenitor origin of human cancer. Nat Rev Genet 2006, 7:2I-33.

37. Ransohoff DF: Developing molecular biomarkers for cancer. Science 2003, 299: |679-|68।.

38. Sakai T, Toguchida J, Ohtani N, Yandell DW, Rapaport JM, Dryja TP: Allele-specific hypermethylation of the retinoblastoma tumor-suppressor gene. Am J Hum Genet I99I, 48:880-888.

39. Amiel A, Litmanovitch T, Lishner M, Mor A, Gaber E, Tangi I, Fejgin $M D$, Avivi L: Temporal differences in replication timing of homologous loci in malignant cells derived from CML and lymphoma patients. Genes Chromosomes Cancer I998, 22:225-23I.

40. Constantinou M, Kaluzewski B, Helszer Z, Zajac E, Nowacka J: Parental detection of maternal UPDI 5 in a new case with i(I5p) by Timing Replication Test (TRT) and methylation analysis. J Appl Gent 2003, 44:209-2I8

4I. Barletta JM, Rainier S, Feinberg AP: Reversal of loss of imprinting in tumor cells by 5-Aza-2'-deoxycytidine. Cancer Res 1997, 57:48-50.

42. Feinberg AP: Imprinting of a genomic domain of I IpI5 and loss of imprinting in cancer. Cancer Res 1999, 59(7 Suppl): I743s-I746s.

43. Feinberg AP: Cancer epigenetics takes center stage. Proc Nat Acad Sci 200I, 98:392-394.

44. Avner $\mathrm{P}$, Heard $\mathrm{E}$ : X-chromosome inactivation: counting, choice and initiation. Nat Rev Genet 2001, 2:59-67.

45. Maxfield Boumil R, Lee JT: Forty years of decoding the silence of the X-chromosome inactivation. Hum Mol Genet 200I, 10:2225-2232.

46. Lyon MF: $\mathbf{X}$-Chromosome inactivation: a repeat hypothesis. Cytogenet Cell Genet 1998, 80: I33-I37.

47. Allen E, Horvath S, Tong F, Kraft P, Spiteri E, Riggs AD, Marahrens $Y$ High concentration of long interspersed nuclear element sequences distinguish monoallelically expressed genes. Proc Natl Acad Sci USA 2003, 100:9940-9945.

48. Gimelbrant A, Hutchinson JN, Thompson BR, Chess A: Widespread monoallelic expression on human autosomes. Science 2007 , 318: I I36-I|40.

49. Sado T, Fenner MH, Tan S-S, Tam P, Shioda T, Li E: X-inactivation in the mouse embryo deficient for DNmt : distinct effect of hypomethylation on imprinted and random $X$ inactivation. Dev Biol 2000, 225:294-303.

50. Egger G, Liang G, Aparicio A, Jones PA: Epigenetics in human disease and prospects for epigenetic therapy. Nature 2004, 429:457-463.

5I. Laired PW: Cancer epigenetics. Hum Mol Genet 2005, I4:R65-R76.

52. Issa J-PJ, Garcia-Manero G, Giles FJ, Mannari R, Thomas D, Faderl S, Bayar E, Lyons J, Rosenfeld CS, Cortes J, Kantarjian HM: Phase I 
study of low-dose prolonged exposure schedules of the hypomethylating agent 5-aza-2'-doxycytidine (decitabine) in hemotopoietic malignancies. Blood 2004, 103:1635-1640.

53. Haaf $\mathrm{T}$ : The effects of $\mathbf{5}$-azacytidine and $\mathbf{5}$-azadeoxycytidine on chromosome structure and function: implications for methylation-associated cellular processes. Pharmac Thern 1995, 65: 19-46.

54. Bjornsson HT, Fallin MD, Feinberg AP: An integrated epigenetic and genetic approach to common human disease. Trends Genet 2004, 20:350-358.

\section{Pre-publication history}

The pre-publication history for this paper can be accessed here:

http://www.biomedcentral.com/1471-2407/8/390/pre pub

Publish with Bio Med Central and every scientist can read your work free of charge

"BioMed Central will be the most significant development for disseminating the results of biomedical research in our lifetime. "

Sir Paul Nurse, Cancer Research UK

Your research papers will be:

- available free of charge to the entire biomedical community

- peer reviewed and published immediately upon acceptance

- cited in PubMed and archived on PubMed Central

- yours - you keep the copyright

Submit your manuscript here:

http://www.biomedcentral.com/info/publishing_adv.asp
BioMedcentral 